Health and Safety Risks in Britain's Workplaces:

Where are They and Who Controls Them?

Alex Bryson

Department of Social Science Working Paper No. 16-05

March 2016 


\section{Disclaimer}

Any opinions expressed here are those of the author(s) and not those of the UCL Institute of Education. Research published in this series may include views on policy, but the institute itself takes no institutional policy positions.

DSS Workings Papers often represent preliminary work and are circulated to encourage discussion. Citation of such a paper should account for its provisional character. A revised version may be available directly from the author.

Department of Quantitative Social Science, UCL Institute of Education, University College London, 20 Bedford Way, London WC1H OAL, UK 


\title{
Health and Safety Risks in Britain's Workplaces: Where are They and Who Controls Them?
}

\author{
Alex Bryson $^{1}$
}

\begin{abstract}
This is the first paper to identify the correlates of workplace managers' perceptions of the health and safety risks faced by workers and the degree to which workers have control over those risks. The risks workers face and the control they have over those risks are weakly negatively correlated. Managerial risk ratings are positively associated with both injury and illness rates, but not with absence rates. The control rating is also positively associated with injury and illness rates, but it is negatively correlated with absence rates. Workers are more likely to be exposed to health and safety risks when their workplace is performing poorly and where it has been adversely affected by the recession. Union density is positively associated with risks but is not associated with worker control over risks. Having on-site worker representatives dealing with health and safety is linked to lower risks than direct consultation between management and employees over health and safety. However, there is no evidence that particular types of health and safety arrangement are related to worker control over health and safety risks.
\end{abstract}

JEL codes: J81

Keywords: Workplace safety; Working conditions; Unions

Contact Details: Alex Bryson (a.bryson@ucl.ac.uk), UCL

Acknowledgements:

I acknowledge the Department of Business, Skills and Innovation, the Economic and Social Research Council, the Advisory, Conciliation and Arbitration Service and the National Institute of Economic and Social Research as the originators of the 2011 Workplace Employee Relations Survey data, and the Data Archive at the University of Essex as the distributor of the data. I thank the Health and Safety Executive and the Norwegian Research Council (ref. 2271l 7/H20) for funding this study and participants at the 2015 WPEG Conference in Sheffield for helpful comments.

\footnotetext{
${ }^{1}$ University College London, National Institute of Social and Economic Research and Institute for the Study of Labor a.bryson@ucl.ac.uk
} 


\section{INTRODUCTION}

For over forty years the health and safety of workers in Britain has been underpinned by a tripartite system of rule making and enforcement. This system, which is based on the Health and Safety at Work Act 1974, is overseen by the Health and Safety Executive and its Board whose mission is "the prevention of death, injury and ill health to those at work and those affected by work activities" (DWP/HSE Framework Document). The HSE Board and its predecessor the Health and Safety Commission, has a tripartite tradition, with appointments from the ranks of employers and trade unions, together with independent experts drawn from academia and industry. These arrangements have proved flexible enough to accommodate substantial changes in the world of work in recent decades, not least the decline in trade union representation which was at its peak in the 1970s. They are generally acknowledged to be a key contributory factor in Britain's good track record in terms of workplace injuries and accidents compared to other advanced industrialised nations. However, the current arrangements for ensuring health and safety at work are not without their critics. Some have even questioned the longer-term viability of existing arrangements and given dire warnings about the consequences of failing to grapple with the need for reform (Wadsworth and Walters, 2015). ${ }^{2}$

Much of the academic literature has focused on the viability and effectiveness of worker inputs to workplace arrangements which, despite creating space for non-union forms of representation, tend to assume that workers will engage in health and safety issues through a trade union recognised by the employer as the bargaining agent for workers.

The rights of workers to certain forms of health and safety representation vary depending upon the presence of a recognised trade union. But clear evidence as to what might constitute the best set of arrangements to protect workers' health and safety remains elusive, in part because of technical difficulties in pinning down the causal effect of alternative arrangements (Nichols et al., 2007). These technical difficulties are common to many scenarios when arrangements come into being in response to perceived problems or difficulties, as in the case of union representation. In such circumstances it is hard to identify whether the arrangement is causally influencing health and safety outcomes, whether it arose in response to health and safety issues, or both. These difficulties are problematic for

\footnotetext{
${ }^{2}$ Nevertheless Wadsworth and Walters (2015: 15) cite evidence from the EU-OSHA's Enterprise Survey on New and Emerging Risks (ESENER) that the UK "seems to score reasonably well" relative to other countries in terms of health and safety management and performance and that this is partly attributable to "the UK's longstanding tradition of process-based health and safety regulation".
} 
policy makers because uncertainty regarding the efficacy of alternative arrangements makes it hard to advocate one course of action over another.

One way to improve the state of knowledge regarding influences on health and safety at work is to exploit experimental variation in health and safety arrangements which may arise naturally or depend upon the design of a policy experiment, such as randomisation of alternative arrangements. Whilst this may appear to be impractical in many instances experimental designs are now common in other spheres of social research such as school education and labour market welfare programmes which are, like health and safety, "high stakes".

In this paper we take a very different approach to the same issue by exploiting new questions, funded in part by the Health and Safety Executive, which were incorporated in to a large-scale national survey of workplaces in Britain called the Workplace Employment Relations Survey (WERS). The survey was conducted between March 2011 and June 2012 at 2,680 workplaces with managers responsible for Human Resources at the workplace. It is discussed in more detail in Section Three. WERS has always contained a wide array of items pertaining to health and safety, particularly in relation to arrangements for discussing and deciding on health and safety matters, who has responsibility for health and safety at the workplace, health and safety training and health and safety related outcomes such as workbased injury and illness and sickness absence. WERS has provided the data for many of the academic contributions to the literature. ${ }^{3}$ But the new questions can provide new insights into occupational safety and health $(\mathrm{OSH})$ because they ask HR Managers to directly assess "the potential health and safety risks faced by employees in this workplace" and "the control that employees have over health and safety risks that could affect them". These two issues - the risks workers face and the control they are able to exercise over those risks - are fundamental to understanding health and safety outcomes at work. These outcomes are beyond the scope of the current paper - although we will briefly show the links between risk, control and injuries, illness and absence. Instead the purpose of this paper is to identify what it is about the working environment which is linked to HR managers scoring their workplaces higher or lower on the "risk" scale and higher and lower on the "control" scale. It is therefore distinctive in two ways. First, it shifts attention away from health and safety outcomes like illness and injury towards factors that contribute to potential health and safety hazards. Second it ranges well beyond the arrangements for engaging employees in health and safety issues - what has been termed the "institutional focus on union

\footnotetext{
${ }^{3}$ For a recent bibliography of WERS publications, including many on health and safety, go to: http://www.wers2011.info/publications/4587720043
} 
representation" (Robinson and Smallman, 2013: 674) - to incorporate a vast array of workplace variables which might, conceivably affect the risks workers face and the control they may exert over those risks. Some of those variables are "structural" in the sense that they are "hard-wired" into certain professions or industries. As such, they may be more difficult (though not impossible) for employers or governments to rectify. Others such as contractual arrangements, job design, the organisation of production and the deployment of human resource management (HRM) practices are more subject to employer choice and, as such, can be altered by employer and employee actions in such a way as to limit risk and improve control.

The analysis of work-related health and safety risks and the degree to which employees have control of them is particularly pertinent from a policy perspective in the light of the Management of Health and Safety at Work Regulations 1999 which set out what Wadsworth and Walters (2015: 9) describe as "broadly based obligations for employers to evaluate, avoid and reduce workplace risks" under the framework provided by the Health and Safety at Work Act. The issue continues to pose challenges for employers and policy-makers alike since as Wadsworth and Walters (2015: 10) note one-sixth of workers surveyed in the 2010 European Working Conditions Survey thought their job risked their health and safety.

In the next section we introduce the measures of health and safety risks and control over those risks as perceived by Human Resource managers in the 2011 Workplace Employment Relations Survey. We present the distribution of these key measures, the correlation between the two, and their relationship with workplace injury, illness and absence rates. Section Three describes the data and methods used to identify the correlates of risks and control. Results are presented in Section Four which is followed by a discussion and conclusions in Section Five.

\section{A BRIEF DESCRIPTION OF HEALTH AND SAFETY RISKS AND EMPLOYEE CONTROL OVER THOSE RISKS}

There is a very substantial literature identifying the health and safety risks employees face at work. Risks are often assessed by employees in social surveys such as the European Working Conditions Survey which asks individuals to identify exposure to specific hazardous situations or substances. There are three potential drawbacks to such measures. First, difficulties interpreting these measures arise partly from employees' misperceptions of the risks they may actually face at work. Individuals consistently underestimate the probability of accidents or illnesses happening at work. This may be due to people using simple heuristic 
devices when making judgements, inbuilt resistance to unwelcome information, or irrational responses to messages about risk which are predicted in some psychological theories (Pouliakas and Theodossiou, 2010: 6-7). Second, by focusing on a specific set of circumstances or substances such measures may omit some risky situations, potentially underestimating the degree of risk that employees face. Since OSH has traditionally focused on the prevention of occupational injuries and illnesses, as opposed to a broader focus on overall protection of workers' health and wellbeing, it seems likely that measures based on traditional measures of risk are more likely to understate risks associated with nonfatal risks. Third, the language of occupational risk prevention brings together the risks employees face and efforts at tackling exposure to that risk, making it difficult to distinguish between the underlying risks employees face and the degree to which employees are able to control those risks.

It was with these concerns in mind that new questions were added to the 2011 Workplace Employment Relations Survey to establish both the risks employees faced at work and the control they had over those risks. Managers are asked to "rate the potential health and safety risks faced by employees in the workplace" on a scale from 1 to 10 where 1 is "no risk at all" and 10 is "high degree of risk". They are then immediately asked to "rate the control that employees have over the health and safety risks that could affect them", again on a 10point scale where 1 is "no control at all" and 10 is "high degree of control".

\section{[INSERT FIGURE 1]}

Figure 1 presents the distribution of responses for all workplaces. Only 19 respondents were unable to provide a risk rating and 12 were unable to provide a control rating. The responses are survey weighted such that they relate to the distribution for the population of workplaces in Britain with at least 5 employees. The figures above the bars represent the percentage of workplaces in that part of the distribution. One-in-ten $(11 \%)$ of managers thought their workers faced "no risk at all", while more than half (54\%) rated risk at 2 or 3 on the 10 point scale. At the other end of the scale, another one-in-ten (11\%) rated risk at 7 or above. Turning to the control rating, one-quarter (26\%) of managers gave a score of 10 , the highest level of employee control over health and safety risks, with a further quarter (27\%) giving a score of 9 . Very few - 7 per cent - rated control below a score of 6 .

The questions are asked of the manager responsible for human resources at the workplace. It is not clear, a priori, whether managers in a position of authority will have better information about the risks specific individuals face and the control they have over health 
and safety risks compared with those individual employees. However, they are likely to possess better information than any individual employee when characterising OSH risks and their control across the whole workplace. ${ }^{4}$

It is uncertain, a priori, what the association might be between health and safety risks employees face and the control they have over those risks. On the one hand employers may be keen to share responsibility for controlling risks at the workplace, especially when those risks are substantial. This might imply a positive correlation between risk and control ratings, something which might seem appropriate if an employer thought that providing employees with such control might mitigate the risks employees faced. On the other hand, in work environments posing high risks employers may choose to "take control" of that risk directly, for example through redesigning jobs or work processes, thus removing this responsibility from employees directly. If this happens then risk and control ratings may be negatively correlated. In fact, the correlation coefficient is negative and statistically significant, though not particularly large $(-0.0809) .{ }^{5}$ If one regresses the control rating on the risk rating having accounted for the complex survey design the coefficient on control is -.098 and is statistically significant at a $95 \%$ confidence interval (t-statistic 2.05). Regressing the risk rating on the control rating the coefficient on risk is -.067 and is statistically significant at a $90 \%$ confidence interval (t-statistic 1.91).

One can split workplaces into those with high risk ratings and high control ratings where high is indicated by having a score above the median for the whole sample. If so workplaces with a risk rating above 3 score "high", as do those with control ratings above 8 . One can then characterise workplaces according to whether they score high or low on each binary variable. If one does so then three-in-ten (29\%) of workplaces are Low Risk, Low Control, over one-third (37\%) are Low Risk, High Control; one-sixth (17\%) are High Risk, Low Control and a further one-sixth (17\%) are High Risk, High Control.

Although measures of work-related risk factors which focus on specific circumstances or exposure to particularly hazardous situations or substances may under-record risk, it is nevertheless the case that they are strongly correlated with health and safety outcomes such as the incidence of work accidents and the occurrence of occupational diseases (Pouliakas

\footnotetext{
${ }^{4}$ It is also unclear as to whether the way in which HR managers weigh the information available to them will differ from other employees.

${ }^{5}$ In the WERS First Findings Van Wanrooy et al. (2013: 39) state: "there was no relationship between managers' rating of health and safety risks and their rating of employees' control of those risks". This is not the case in the final data set. There may be a number of reasons for this, including alterations made to sampling weights during the finalisation of the data.
} 
and Theodossiou, 2010: 9). One way to validate the risk and control scales in WERS is to ascertain whether they are correlated with health and safety outcomes. The results are presented in the correlation matrix in Table 1.

\section{[INSERT TABLE ONE]}

The table contains three health and safety outcomes, namely the absence rate (percentage of work days lost through employee sickness or absence in the last 12 months), the injury rate (number of injuries during working hours per 100 employees in the last 12 months) and the illness rate (number of employees per 100 employees who, in the last 12 months, suffered illness, disability or physical problems caused or made worse by their work and who were absent as a result). The risk rating is positively associated with both injury and illness rates, but not with absence rates. The control rating is also positively associated with injury and illness rates, but it is negatively correlated with absence rates suggesting that, if employee control over health and safety risks mitigates the adverse effects of risk, this is most apparent in terms of how employees respond to illness and injury in terms of absence taking. ${ }^{6}$

\section{DATA AND METHODS}

Having briefly introduced managerial ratings for the health and safety risks facing employees and the degree to which they have control over those risks we describe the data and methods used to conduct multivariate analysis of the workplace correlates of risk and control.

The descriptive analyses in Section Two have two implications for the way in which we model risk and control ratings. First, the distribution of responses on both questions are far from normally distributed and it is therefore likely that the error terms in any linear model estimating these variables as outcomes are not going to be normally distributed. We nevertheless run Ordinary Least Squares (OLS) models which assume a normal distribution in the error terms, but we do so having logged the risk and control variables referred to above. We also run survey weighted estimates which permit extrapolation of results to the whole population of workplaces from which WERS is drawn, namely those with 5 or more employees. In doing so we deploy a robust estimator that takes account of the heteroskedastic pattern in the error terms.

\footnotetext{
${ }^{6}$ These associations are worthy of further investigation but they fall beyond the scope of the current project.
} 
Second, there is a negative, albeit fairly weak, correlation between risk and control ratings. It is conceivable that this arises because risk and control are, at least to some degree, simultaneously determined. We run some sensitivity tests which account for unobserved correlations between the risk and control ratings but the results do not change very much so we focus on standard OLS estimates. ${ }^{7}$

Our data are the 2011 Workplace Employment Relations Survey (WERS). Appropriately weighted, it is a nationally representative survey of workplaces in Britain with 5 or more employees covering all sectors of the economy except agriculture and mining (van Wanrooy et al., 2013b). ${ }^{8}$ Our analysis uses one element of the survey, namely the face-to-face interview with the most senior workplace manager responsible for employee relations. ${ }^{9}$ Interviews were conducted in 2,680 workplaces between March 2011 and June 2012 with a response rate of $46 \%$.

Our multivariate analyses condition on five sorts of control variables which are entered simultaneously into the models for risk and control ratings. The precise configuration of variables used in the models presented in Section Four is the product of considerable experimentation. Some variables which one might expect to see in the analysis are dropped after exploratory analyses indicating that they have no significant relationship with risk and control ratings. However, most of these variables, and others which were considered, were statistically non-significant or were not robust to various model specifications. We discuss some variables that do not appear in our final models where they are viewed as either theoretically important or have been identified as potentially significant in earlier studies.

The first set of variables that we use in our models are "hard-wired" into the workplace, in the sense that although they are, conceivably, subject to alteration via managerial decisionmaking, they can nevertheless be treated as pre-determined or "structural". These variables are:

- the number of employees at the workplace

- public sector organisation

- region (11 dummies)

- industry (1-digit, 2-digit and 5-digit classifications)

\footnotetext{
${ }^{7}$ They confirm the negative correlation in the error terms between these two equations. Results from these seemingly unrelated regressions (SUR) are available from the author on request.

${ }^{8}$ Some sectors, notably agriculture and fisheries and mining are excluded from the survey.

${ }^{9}$ Surveys are also conducted with employees and worker representatives but analysis of these surveys lies outside the scope of this study. For more information on WERS go to http://www.wers2011.info/
} 
- occupational mix (the largest non-managerial occupational group)

- workforce composition (percent female).

We experimented with different models according to the degree to which we control for detailed industrial classification. As is well-known from the literature, much of the variance in the job-related risks that employees face are a direct result of the type of job they do and the industry they work in. It is therefore important to account for that variance adequately. Failure to do so can induce omitted variables bias wherein some correlations between other variables of interest, such as management practices, may, in fact, simply reflect industry variance in the incidence of those practices. One has to be cautious, however, when controlling for very detailed industry classification given that the total number of workplaces in our estimation sample is around 2,580. Nevertheless, it is very striking how much of the variance in risk and control ratings is linked to the industry to which the workplace belongs, as indicated in Table 2.

\section{[INSERT TABLE 2]}

Running models that control for industry classification alone nine per cent of the variance in risk ratings across workplaces can be accounted for by single digit industry. This rises to $16 \%$ when switching to a two-digit classification and $41 \%$ with a five-digit classification. $A$ similar pattern emerges with respect to control ratings, although in all models the variance explained is lower for control ratings than it is for risk ratings, rising from $2 \%$ with single digit industry to $21 \%$ with 5-digit industry. In the analyses presented in Section Four we focus on models incorporating two digit industry. In doing so we are essentially exploring variance in risk and control ratings within two-digit industry.

The second set of variables identify who the managerial respondent is. These variables, interesting in their own right since they identify which sorts of HR managers give higher and lower risk and control ratings, are primarily included to soak up "noise" in our estimates associated with systematically different perceptions of different types of manager and differences associated with their competence to judge on such matters, as well as how well informed they might be about health and safety matters. These variables are:

- whether the manager is female

- whether the manager, or someone who is responsible to the manager, has formal responsibility for health and safety matters at the workplace

- the manager's formal job title (4 dummy variables). 
The third set of variables used in our analyses relate to the market for goods or services in which the workplace operates. This is partly captured, of course, by industry classification, but WERS contains a plethora of information about the configuration of the market for goods and services - the location of the market, the number of competitors the workplace faces, the workplace's market share - and changes in market conditions, all of which may have a bearing on health and safety risks and control. The market variables we focus on in our analyses are:

- the extent to which the manager agrees the workplace is "now weaker as a result of its experience of the recent recession" (a five point Likert scale entered as a linear term)

- an additive scale for the performance of the workplace relative to the industry average. ${ }^{10}$

The fourth group of variables used in these analyses are policies, practices or procedures over which managers, either at workplace-level or elsewhere in multi-site organisations, exercise considerable discretion. As such they are more akin to "choice" variables than those discussed above. The fact that they are "choice" variables means it is not possible to make causal inferences about their impact on risk and control ratings using cross-sectional data. This is because managers' choices as to the practices and procedures they deploy may be simultaneously determined with the risks and control employees face at the workplace. They may even be a response to the health and safety situation leading to reverse causality. Managers will be aware, at least imperfectly, of the costs and benefits of deploying certain policies and practices, including those relating to health and safety costs and benefits. It is likely, therefore, that those policies and practices may be endogenous with respect to our outcomes of interest making causal inferences problematic. ${ }^{11}$

\footnotetext{
${ }^{10}$ This additive scale, which runs from 0 to 9 , where 0 is the poorest performance and 9 the highest, combines responses from three items asking the manager "Compared with other workplaces in the same industry how would you assess your workplace's....financial performance, labour productivity, quality of product or service?" The responses identify whether the workplace is "a lot better than average", "better than average", "about average", "below average" and "a lot below average". In summing the items we combine the small number of observations that are below or a lot below average.

${ }^{11}$ Causal inferences can be made when practices are randomly assigned either across or within workplaces, but this is rarely done in the case of health and safety matters. There may also be opportunities to exploit exogenous variation in policies and practices arising from natural experiments such as those relating to changes in government policy. In the absence of such sources of exogenous variance analysts often deploy instrumental variables techniques. Examples using WERS data include Fenn and Ashby (2004) and Robinson and Smallman (2006). However, the identification assumptions are often subject to criticism due to the use of weak instruments or the difficulties faced in credibly maintaining that the instruments can reasonably be excluded from the outcome equation (the exclusion restriction). It would be possible for us to identify the
} 
With these caveats in mind we distinguish between policies, practices and procedures falling within four domains. The first domain relates to the organisation of production at the workplace and is characterised using the following variables:

- a dummy variable capturing the presence of fully autonomous team working ${ }^{12}$

- the percentage of core non-managerial employees organised into teams

- functional flexibility on the part of core non-managerial employees, as indicated by actually doing jobs other than their own at least once a week

- the number of financial incentive schemes at the workplace ${ }^{13}$

- $\quad$ an additive job autonomy scale. ${ }^{14}$

The second domain is the contractual arrangements the workplace uses for its workers. We investigated the role of annual hours contracts, zero hours contracts, temporary agency workers, freelancers, home-working, fixed-term contracts, part-time working, and shift-work, as well as an additive scale for non-standard contracts (summing all these contracts except part-time working which is widespread). Our final models retain a simple dummy variable identifying shift-working.

The third domain is what might be loosely termed "human resource management (HRM) practices". Again, WERS contains a very broad array of such practices, many of which were incorporated in our models but were either statistically non-significant or were not robust to alternative model specifications. ${ }^{15}$ The final set of HRM practices used in our models relate directly or indirectly to health and safety issues. They are:

- The workplace has targets for absenteeism

- The workplace has targets for employee job satisfaction

antecedents to control and risk ratings in 2011 using predictors from the 2004 WERS for panel cases, but this is beyond the scope of the current study.

12 These are workplaces where core non-managerial employees operate in teams where "team members depend on each other's work to be able to do their job", "team members jointly decide how the work is to be done", and "teams are given responsibility for specific products or services".

${ }^{13}$ The additive scale is based on the number of the following schemes used: merit pay; individual payment-byresults; team-based payment-by-results; workplace-based payment-by-results; organization-level payment-byresults; share ownership scheme; profit-related pay scheme.

14 The additive scale runs from 0 to 12 scoring workplaces according to the degree to which core nonmanagerial employees have "variety in their work", "discretion over how they do their work"; "control over the pace at which they work"; and "involvement in decision over how their work is organised". The subscales run from "None" (zero) to "a lot" (three).

${ }^{15}$ These included training a high percentage of core employees off-the-job; quality circles; Investors in People award; use of appraisals; strategic planning; benchmarking; keeping of records; eligibility for flexible arrangements for time off work. 
- Core non-managerial employees have health and safety training

- Whether managerial and non-managerial employees have sick pay entitlements "in excess of statutory requirements".

The fourth domain, which has perhaps been the most widely explored in the literature to date, is the arrangements for worker representation via trade unions and other mechanisms. Here we focus on three sets of variables:

- the percentage of employees at the workplace belonging to a trade union

- whether there is a trade union at the workplace and, if so, whether the employer informs, consults or negotiates with the union over health and safety matters, or does nothing

- the arrangements for engaging employees over health and safety matters, distinguishing between direct consultation, use of a joint committee, use of worker representatives, or doing nothing.

These three items overlap in such a way that they cannot be entered together in the same equation. Instead we experiment with different combinations.

The fifth and final group of variables used in our analyses are managerial attitudes to aspects of management. We use three 5-point scales capturing the degree to which the manager agrees with the following statements:

- "Unions help find ways to improve workplace performance"

- "We would rather consult directly with employees than with unions"

- $\quad$ "We do not introduce any changes here without first discussing the implications with employees"

In capturing part of managerial style and orientation they are interesting in their own right, but they might also capture some of what lies behind managers' choices in terms of health and safety arrangements. These attitudes are incorporated as a sensitivity check when exploring the association between risk and control ratings and worker representation and health and safety arrangements.

We use dummy variables to capture instances in which workplaces have missing data on particular items, thus limiting the loss of observations due to missing data. Our final estimation sample is between 2,579 and 2,584 depending on the model. 


\section{RESULTS}

Our baseline results are presented in Table 3. The model specifications are identical for the two dependent variables log risk rating and log control rating.

\section{[INSERT TABLE 3]}

Perceptions of health and safety risks and employee control of those risks differ with the characteristics of managerial respondents. Finance Managers and, to a lesser extent, Owner Managers and General Managers, give lower risk ratings than their professional HR Manager counterparts whose expertise is signalled by their job title. ${ }^{16}$ Perceptions of control do not differ according to the manager's job title. Those who are directly responsible for health and safety matters at the workplace perceive employee control of health and safety risks to be a little greater than those who do not have direct responsibility. Managers' gender also matters: ceteris paribus female HR managers think employees face greater risks and have less control over those risks than their male counterparts.

There is a substantial literature pointing to the importance of firm size and, in particular, the distinction between small, medium-sized and large organisations, in determining job-related risks, health and safety outcomes and worker wellbeing. For example, using the 2004 WERS Forth et al. (2006) find job satisfaction differs by firm size. Reviewing the literature Pouliakas and Theodossiou (2010: 15) suggest health and safety risks are greatest in medium-sized companies. The hypothesis underpinning a number of studies is that larger organisations are better able to devote resources to controlling health and safety risks, either through supervision, training and support or thorough risk assessments, than smaller organisations. However, variables capturing organizational size, such as whether the workplace belonged to a larger organization, firm size, and the number of establishments owned by the organisation, were not statistically significant. We retained the number of employees at the workplace in the model but this is also statistically non-significant (as was a squared term which has been removed).

However, two other "structural" features of the workplace were statistically significant having accounted for industry affiliation. Public sector employees faced lower risks than their private

\footnotetext{
${ }^{16} \mathrm{HR}$ specialists are indicated with job titles such as "Human Resource Manager" or "Manager of Employment Relations".
} 
sector counterparts, but they were also thought to have less control over those risks. ${ }^{17}$ The location of the workplace also mattered: the regional dummies are jointly statistically significant in both the risk and control models. ${ }^{18}$ However, it is difficult to find a rationale for the pattern of regional effects. Workplaces in the North East, the East of England, and the West Midlands appear to have the lowest risk ratings whilst the East Midlands and the South East (which is the reference category) have the highest. Differences are less pronounced with regard control ratings: workplaces in the North East have the highest control ratings while Wales and Scotland have the lowest.

Since different occupations carry different levels of risk (Smallman, 2001) it is hardly surprising to find that the occupational mix at the workplace is strongly linked to managers' risk ratings. The single-digit occupational classification for the largest non-managerial occupational group is jointly statistically significant in the risk ratings model. Workplaces where the largest occupation is Skilled Trades or Process, Plant or Machine Operatives had significantly higher risk ratings than those whose largest occupational group was Professionals (the reference category). However, the occupational composition of the workplace is not significantly associated with control ratings. ${ }^{19}$

If individuals with relatively poor human capital or low bargaining power find it necessary to take up jobs that others prefer to avoid one might expect an association between proxies for poor human capital and low bargaining power to be positively associated with risk ratings and negatively correlated with control ratings. Proxies might include the percentage of ethnic minority employees, the percentage of migrants (distinguishing those from the European Economic Area and those from elsewhere), and the percentage disabled. However, none of these were robustly associated with risk and control ratings.

The percentage of females in the workforce, on the other hand, was negatively associated with risk ratings, though it was not related to control ratings. One might have expected a negative association between the percentage of females at the workplace and risk ratings given gender differences in the occupations and tasks men and women tend to perform, but the finding persists even though the models contain fairly detailed controls for the nature of the work being undertaken at the workplace. It is possible that the percentage female is

\footnotetext{
${ }^{17}$ This finding is worthy of further examination given the strong correlations between industrial sector, worker representation and public sector. For instance, split analyses for the public and private sectors may be informative.

${ }^{18}$ We use Wald tests to establish whether sets of variables are jointly significant (the testparm command in STATA).

${ }^{19}$ Similar findings emerge if we use the percentage of employees in each occupational classification.
} 
picking up differences in human capital or bargaining power not otherwise accounted for by the model. Alternatively, women may sort into less risky jobs, as might be predicted by the literature indicating that women are more risk-averse than men (Grazier and Sloane, 2008).

There are a number of reasons why one might anticipate a link between health and safety risk and control ratings and workplace performance. For example, workplaces performing poorly relative to others in their industry, or as a result of the recent recession, may face greater difficulties in devoting the time and resource needed in ensuring health and safety matters are adequately addressed at the workplace. Table 3 confirms that the additive performance scale is negatively associated with risk ratings, whereas the perception that the workplace was weakened by the recession is positively associated with risk ratings. However, workplace performance is not associated with employee control over those risks.

Next we turn to the policy and practice domains over which employers have a reasonable degree of choice. We begin with the five items capturing managerial discretion over the way work is organised and rewarded. These prove more important in explaining variance in employee control over health and safety risks than they do in accounting for variance in risk ratings. Taken together these five practices (the extent of team-working, the degree of autonomy teams had, job autonomy, functional flexibility and the incidence of financial incentives) are jointly highly statistically significant in the control ratings models but are only on the margins of statistical significance (at a $90 \%$ confidence level) in the risk ratings models.

Neither the extent to which employees are working in teams nor the autonomy those teams have are significantly associated with the degree of risk employees face. But both are linked to control of those risks, albeit in different ways. Control ratings rise with the percentage of employees working in teams, but fall with the degree to which those teams are fully autonomous of the managerial hierarchy. ${ }^{20}$ This second finding is consistent with Robinson and Smallman's (2006: 99) conjecture that "a situation in which too much freedom and a lack of clear guidelines or procedures about how work is to be done may be counterproductive". An alternative conjecture is that the degree to which teams operate autonomously is an indicator of the degree to which team-working entails labour intensification, as opposed to a

\footnotetext{
20 This may partly explain Robinson and Smallman's (2006: 98) finding that, at least in manufacturing, autonomous team working is associated with higher injury rates when compared to semi-autonomous team working.
} 
means of job enrichment as it is often characterised in the HRM literature (Wood and Bryson, 2009). ${ }^{2122}$

Worker autonomy at the job-level - as indicated by an additive scale capturing the degree to which core non-managerial employees have variety in their work, discretion over how they do their work, control over the pace at which they work and involvement in decision over how their work is organised - is positively associated with control ratings but is not associated with risk ratings. ${ }^{23}$

By linking pay to performance, either at individual, group or organisation level, incentive pay systems are often identified as mechanisms encouraging employees to work harder than they might otherwise have done under a fixed pay contract where employees are paid for the time they work. They therefore have the potential to increase health and safety risks where workers increase the pace at which they are working. The desire to raise output under performance pay contracts may also encourage workers to limit the time they spend "offline" in training, or in servicing equipment, potentially increasing risk and reducing employee control over health and safety risks. In fact the number of incentive schemes used at the workplace was negatively associated with risk ratings and was not significant in the control ratings models.

The only work organisation practice significantly associated with both risk and control ratings was functional flexibility on the part of core non-managerial employees as indicated by actually doing jobs other than their own at least once a week. This practice, often advocated by HRM practitioners as a means of increasing work efficiency and minimising costs, is significantly associated with higher risk ratings and lower control ratings.

\footnotetext{
${ }^{21}$ In earlier versions of the model we incorporated a dummy variable capturing just-in-time production. This was not associated with risk ratings, but it was negatively associated with control ratings. However, the finding was not robust to alternative model specifications.

${ }^{22}$ The literature on sickness absence focuses on the degree to which workers are complements or substitutes for one another. It generally finds absence taking is lower where workers are complements, especially when combined with team incentives, because the absence of a small number of workers can substantially reduce team output.

${ }^{23}$ Analyses of the 1998 WERS suggest that the association between job autonomy and injuries and illnesses is a little more complex. Control over the pace of work is associated with lower injury and illness rates in both manufacturing and services. Having a lot of variety in one's work is positively associated with illness in services but negatively associated with injury in manufacturing. Discretion over how one performs one's job tasks is strongly positively associated with illnesses in the manufacturing sector (Robinson and Smallman, 2006: 9799). These complex relationships suggest more investigation of job autonomy and its components might be merited.
} 
Manager-initiated work reorganisation adversely affects employees' subjective wellbeing (Bryson et al., 2013). It is also possible that such workplace innovations could disrupt procedures, policies and ways of doing things in a way that creates new health and safety risks, or reduces employee control over those risks. We therefore tested the association between managerial innovations over the previous two years and risk and control ratings. There was no association so these variables are omitted from the model. ${ }^{24}$

Employers also exercise choice over work organisation by deciding what sorts of employment contracts they will offer to their staff, and the extent to which they resort to flexible forms of labour to complement their core staff. We investigated the role of annual hours contracts, zero hours contracts, temporary agency workers, freelancers, homeworking, fixed-term contracts, part-time working, and shift-work, as well as an additive scale for non-standard contracts (summing all these contracts except part-time working which is widespread). The value of contingent contracts from an employer perspective is that they offer greater flexibility over hiring and firing decisions, and enable employers to bring in staff for short periods to perform discrete tasks, or to meet fluctuations in demand for goods or services, without incurring the costs that labour adjustments may entail when dealing with permanent employees. From a health and safety perspective, however, they may increase the complexity of work organisation as permanent staff seek to coordinate and work alongside those in non-standard contracts. Workers on such contracts may be less familiar with working practices at a particular workplace, and employers may be less inclined to train them and explain health and safety procedures to them. For these reasons one might anticipate that they are linked to higher risk ratings and lower control ratings. In general this proved not to be the case so variables capturing these contingent contracts are excluded from the model. The only exception is shift-working, a form of contract which is often offered to permanent staff. Shift-working is associated with employees facing higher health and safety risk, but it is not associated with control ratings. The result is unsurprising given the association between increased injury probabilities and shift-working found in other studies (Robinson and Smallman, 2006: 98). ${ }^{25}$

\footnotetext{
24 The survey items are based on the question: "Over the last two years has management here introduced any of the changes listed on this card.... Introduction of performance related pay; Introduction or upgrading of new technology (including computers); changes in working time arrangements; changes in the organisation of work; changes in work techniques or procedures; introduction of initiatives to involve employees; introduction of technologically new or significantly improved products or services".

25 Pouliakas and Theodossiou (2010: 14) review the literature indicating that a variety of working time arrangements adversely affect workers' physical and psychological health through a range of mechanisms such as exhaustion and interruption to sleep patterns.
} 
There is renewed interest in the potential value of target setting, performance monitoring via record systems, and incentive structures following the work of Bloom et al. (2014) indicating an association between management practices (sometimes loosely termed "HRM practices") and firm productivity. Their relationship to workplace health and safety has not been examined so systematically. We investigated a wide range of potential indicators to establish what correlation, if any, they had with risk and control ratings. Many were not associated with either outcome. ${ }^{26}$ The subset of five practices retained in Table 3 are jointly statistically significant in both models. In general, setting targets was not significantly associated with risk and control ratings, but there were two exceptions. Targets for absence were negatively associated with employees having control over the health and safety risks they faced, as might be expected if employers wishing to pro-actively manage the risks employees faced chose to do so through top-down management practices. Targets for employee satisfaction, on the other hand, are positively associated with control ratings. The literature indicates that employee satisfaction rises with job control (Bryson et al., 2014) so it is perhaps unsurprising to find that employers targeting employee job satisfaction are prepared to cede control over health and safety risks to their employees. Neither target was significantly correlated with risk ratings.

Health and safety risk ratings are higher in workplaces reporting that core non-managerial employees are given health and safety training. In a similar vein Robinson and Smallman (2006: 98) find OSH training is positively correlated with injuries and illnesses in the service sector. Both sets of findings do not necessarily indicate training is ineffective in tackling risks. It is equally plausible that employers only offer training in circumstances where they perceive the risks to be higher, that is, the training measure is endogenous with respect to risk. Nevertheless it is informative to note that $\mathrm{OSH}$ training is not associated with greater employee control over risks, as one might have expected in training provided employees with means to take control over the risks they face.

Whether employers choose a sick pay scheme offering employees entitlements above the statutory minima is potentially informative about employers' preparedness to compensate employees for the risks they face at work. If viewed as a fringe benefit for employees running higher health and safety risks, it might be positively correlated with risk ratings, just as one might anticipate a positive correlation between wages and risk if higher wages were

\footnotetext{
${ }^{26}$ These included benchmarking against other workplaces ("examining the ways things are done at other workplaces and comparing them with this workplace"); award of Investors in People; strategic planning; quality circles; the extensive use of off-the-job training; and the maintenance of records in relation to matters such as sales, costs, profits, productivity, quality of output, labour turnover, absenteeism, and workforce training.
} 
operating as a compensating wage differential. ${ }^{27}$ If payment of sick pay above the statutory minima is an indicator of an "enlightened" employer concerned with employee welfare this might be positively correlated with the employer's propensity to cede control over health and safety risks to employees. Neither conjecture is supported in the models: sick pay arrangements are not significantly correlated with control or risk ratings.

Our final set of variables in the model are those capturing worker representation at the workplace on health and safety matters and more generally. The literature referred to earlier focuses largely on the relationship between worker representation and injury and illness rates. The analysis here is different in that it focuses on managerial perceptions of health and safety risks and employee control over those risks. Consequently, our analyses do not have to contend with the difficulty in interpreting associations when workers with stronger forms of representation are more likely to report a given accident, injury or occupational illness.

It is well-established that worker demand for union representation rises with the problems employees face at work (Bryson and Freeman, 2013). This is likely to mean that union presence and the strength of a given union, as indicated by the percentage joining the union (union density) will be endogenous in models estimating risk ratings. One might therefore expect them to be positively correlated. Some earlier studies have sought to tackle the endogeneity of union status using instrumental variables. This has not been attempted in the current draft of the paper.

One might anticipate a positive correlation between unionisation and control ratings if worker representatives are successful in mitigating risks by bargaining in favour of more employee control over risks.

As in earlier papers we distinguish between union incidence and the nature of worker representation in health and safety matters. The latter are captured by the formal nature of health and safety arrangements but also, in alternative models, by the nature of union involvement in health and safety - specifically whether the employer negotiates with the union over health and safety matters, consults the union, simply informs the union or does nothing at all.

\footnotetext{
${ }^{27}$ For a review of the literature on poor working conditions, health and safety risks and compensating differentials see Pouliakas and Theodossiou (2010). We entered the percentage of employees in different wage bands into our regressions but the wage distribution was not statistically significant in either the risk or control models.
} 
In investigating the association between worker representation and risk and control ratings we check the sensitivity of results to the inclusion of the three managerial style variables discussed in the last section which identify the manager's attitudes towards dealing with unions versus dealing directly with employees.

As anticipated, there is a positive statistical association between union density and risk ratings suggesting, perhaps, that worker demand for union representation rises with health and safety risk. However, union density is uncorrelated with control ratings. This is the case whether or not one controls for the level of risk at the workplace and regardless of whether one controls for managerial attitudes. ${ }^{28}$ If one treats union density as a proxy for union bargaining power the implication is that it has little bearing on employees' ability to control the health and safety risks they face at work.

Conditioning on union density, Table 3 shows arrangements for worker representation on health and safety matters makes little difference to control ratings but, relative to the reference category of direct consultation between management and employees, having worker representatives is associated with lower risk ratings. There is no difference in risk ratings in workplaces with joint committees relative to those with direct consultation.

Some observers argue that the rights to worker representation on health and safety matters are weaker in non-unionised workplaces in spite of legislative changes in the 1990s (Robinson and Smallman, 2006: 88). We therefore split the sample according to whether the workplace had a recognised trade union. Links between representation and risk and control ratings did not differ significantly in the two sectors.

In the union sector we are also able to distinguish between scenarios in which the employer negotiates, consults, informs or does not engage with a union over health and safety. However, these variables were not jointly statistically significant in either the risk or control models.

\footnotetext{
${ }^{28}$ When introduced into the control rating model reported in Table $3 \log ($ risk) is negative and statistically significant $(-.07, \mathrm{t}$-stat $=2.92)$ but the coefficients on union density are essentially unchanged. When introduced into the control rating model reported in Table 3 the three employer attitudes variables are jointly statistically non-significant and have no bearing on union density.
} 


\section{SUMMARY AND CONCLUSIONS}

To our knowledge this is the first analysis of managerial ratings of health and safety risks and their workplace and employee control over those risks. We are able to do so because new questions, sponsored by the Health and Safety Executive, were inserted into the 2011 Workplace Employment Relations Survey. Appropriately weighted, this is a nationally representative survey of all workplaces in Britain with at least 5 employees. Although earlier versions of the survey have been used extensively to explore the correlates of workplace injuries and illnesses, the prime focus of this literature has been the arrangements for worker representation in health and safety matters. This started to change a few years ago, with growing interest in non-union forms of information, communication and consultation. This paper takes this broader focus a step further by investigating the associations between an array of workplace practices and policies that may impinge upon the risks workers face in the workplace and their ability to control those risks.

This is the first paper to identify the correlates of workplace managers' perceptions of the health and safety risks faced by workers and the degree to which workers have control over those risks. The risks workers face and the control they have over those risks are weakly negatively correlated. Managerial risk ratings are positively associated with both injury and illness rates, but not with absence rates. Control ratings are also positively associated with injury and illness rates, but they are negatively correlated with absence rates. Workers are more likely to be exposed to health and safety risks when their workplace is performing poorly and where it has been adversely affected by the recession. Union density is positively associated with risks but is not associated with worker control over risks. Having on-site worker representatives dealing with health and safety is linked to lower risks than direct consultation between management and employees over health and safety. However, there is no evidence that particular types of health and safety arrangement are related to worker control over health and safety risks. 


\section{REFERENCES}

Bloom, N., Lemos, R., Sadun, R., Scur, D. and Van Reenen, J. (2014) "The New Empirical Economics of Management", NBER Working Paper No. 20102

Bryson, A., Dale-Olsen, H. and Barth, E. (2013) 'The Effects of Organizational Change on Worker Wellbeing and the Moderating Role of Trade Unions', Industrial and Labor Relations Review, 66, 4: 989-1011

Bryson, A. and Freeman, R. B. (2013) 'Employee Perceptions of Working Conditions and the Desire for Worker Representation in Britain and the US', Journal of Labor Research, 34, 1: $1-29$

Bryson, A., Forth, J. and Stokes, L. (2014) Does Worker Wellbeing Affect Workplace Performance? Department for Business, Innovation and Skills

Fenn, P. and Ashby, S. (2004) "Workplace risk, establishment size and union density", British Journal of Industrial Relations, 42, 3: 461-480

Forth, J., Bewley, H. and Bryson, A. (2006) Small and Medium-Sized Enterprises: Findings from the 2004 Workplace Employment Relations Survey, London: Department of Trade and Industry

Grazier, S. and Sloane, P.J., (2008) "Accident risk, gender, family status and occupational choice in the UK", Labour Economics, 15, 5: 938-957

Nichols, T., Walters, D. R. and Tasiran, A. C. (2007) "Trade unions, institutional mediation and industrial safety: evidence from the UK", Journal of Industrial Relations, 49, 2: 211-225

Pouliakas, K. and Theodossiou, I. (2010) "An Inquiry Into The Theory, Causes and Consequences of Monitoring Indicators of Health and Safety at Work", SIRE Discussion Paper No. 120

Robinson, A. M. and Smallman, C. (2006) "The contemporary British workplace: a safer healthier place?" Work, Employment and Society, 20, 1: 87-107

Robinson, A. M. and Smallman, C. (2013) "Workplace injury and voice: a comparison of management and union perceptions", Work, Employment and Society, 27, 4: 674-693

Smallman, C. (2001) "The Reality of 'Revitalising Health and Safety'", Journal of Safety Research, 32, 4: 391-439

van Wanrooy, B., Bewley, H., Bryson, A., Forth, J., Freeth, S., Stokes, L. and Wood, S. (2013a) The 2011 Workplace Employment Relations Study First Findings, ESRC/ACAS/NIESR/DBIS 
van Wanrooy, B., Bewley, H., Bryson, A., Forth, J., Stokes, L. and Wood, S. (2013b) Employment Relations in the Shadow of Recession: Findings from the 2011 Workplace Employment Relations Study, Palgrave MacMillan

Wadsworth, E. and Walters, D. (2015) "The Determinants of Workplace Health and Safety Practice in the UK", Policy and Practice in Health and Safety, 12, 2: 3-22

Wood, S. and Bryson, A. (2009) 'High involvement management', Chapter 7 in W. Brown, A. Bryson, J. Forth and K. Whitfield (eds.) The Evolution of the Modern Workplace, pp. 151175, Cambridge University Press 
Figure 1: Risk and Control Ratings

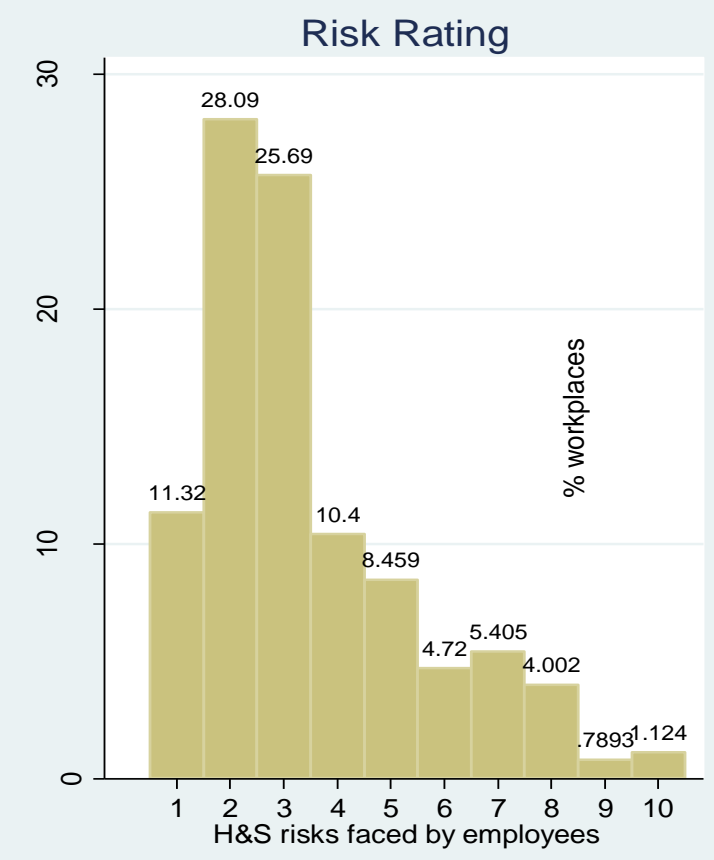

Control Rating

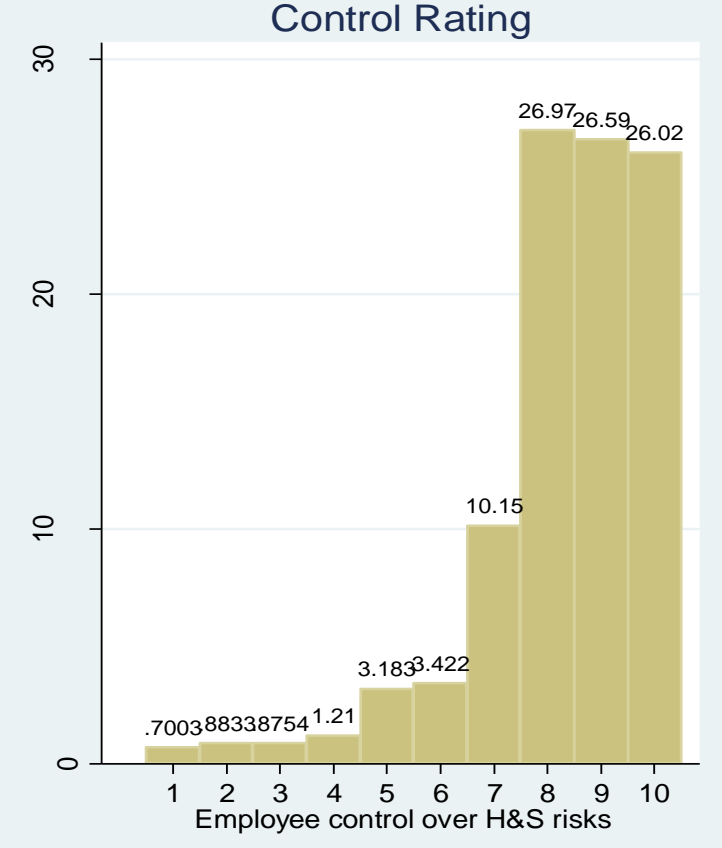


Table 1: Correlation Matrix for Risk, Control, Absence, Injury and Illness

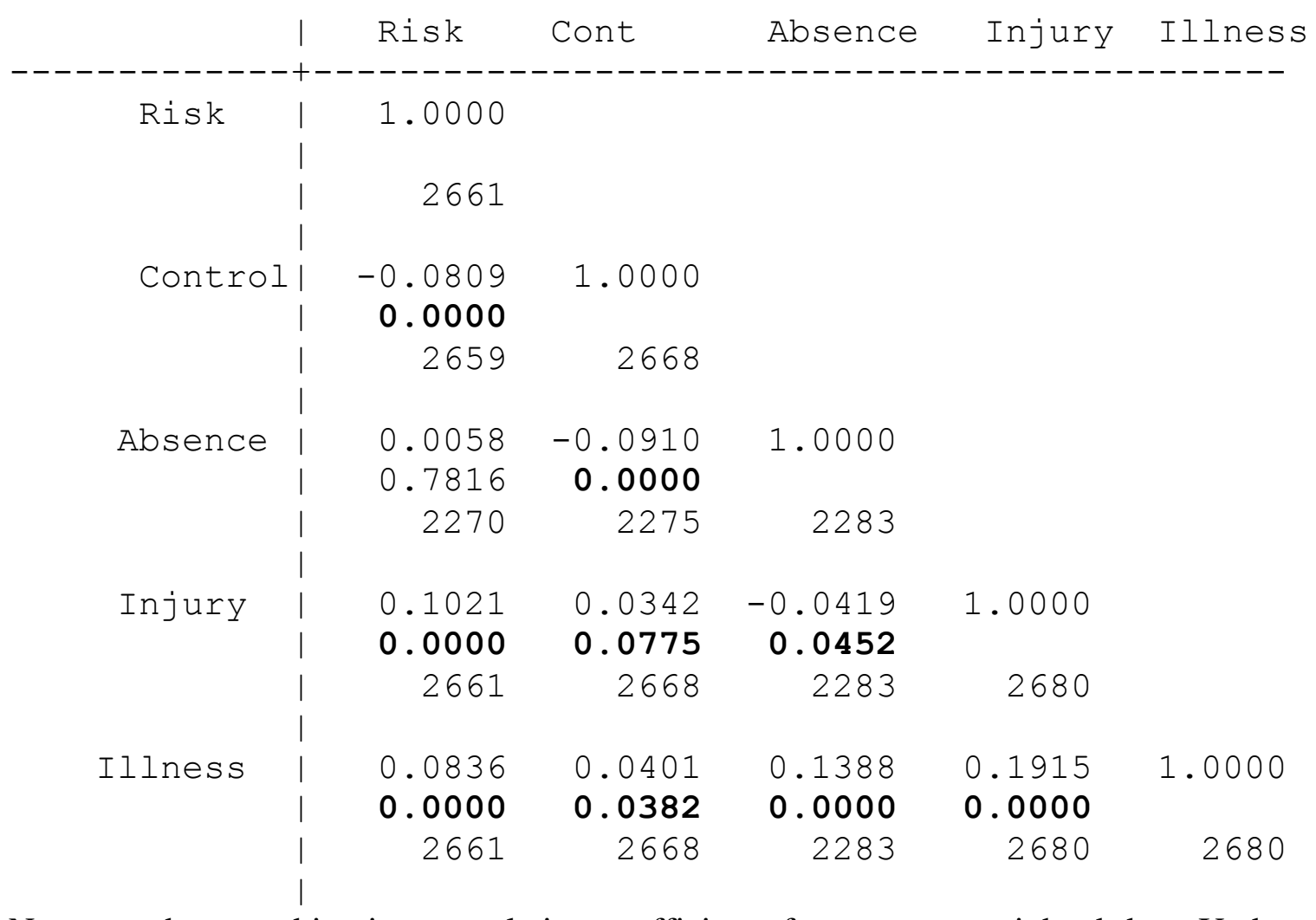

Note: numbers are bivariate correlation coefficients from survey weighted data. Underneath each coefficient is the p-value and the unweighted number of workplaces on which the correlation is based. Statistically significant p-values are in bold. 
Table 2: The Variance in Log Risk and Log Control Ratings Accounted for by Industry Alone

\begin{tabular}{|l|l|l|l|l|l|l|}
\hline \multicolumn{2}{|l|}{ 1-digit SIC } & \multicolumn{2}{l|}{ 2-digit SIC } & 3-digit SIC \\
\hline & Risk & Control & Risk & Control & Risk & Control \\
\hline r-squared & .093 & .021 & .162 & .030 & .410 & .215 \\
\hline Unwted N & 2661 & 2668 & 2661 & 2668 & 2661 & 2668 \\
\hline
\end{tabular}


Table 3: Log Risk and Control Models

Risk

Control

Respondent characteristics:

Female

H\&S responsibilities

0.08
$(2.03)$
0.05

(1.19)

$(-1.85)$

Job Title (ref.: HR Manager)

Owner/general manager

$-0.08 \quad-0.03$

$(-1.64)$

$(-1.08)$

Finance Manager

$-0.3$

0.03

$(-4.70)$

Other

$0.23 * * \quad-0.05$

(2.21)

$(-0.74)$

Workplace characteristics:

Region (ref: South East)

Yorkshire and Humberside

$\begin{array}{ccc}-0.03 & & -0.02 \\ (-0.34) & & (-0.33) \\ -0.16 & * * & -0.01 \\ (-2.13) & & (-0.20) \\ -0.2 & * * & 0.08 \\ (-2.15) & & (2.25) \\ -0.2 & * * * & 0.02\end{array}$

East of England

$(-2.68)$

(0.54)

East Midlands

0.05

$-0.01$

(0.57)

$(-0.31)$

West Midlands

$-0.18$

0.05

$(-2.60)$

$-0.22$

(1.49)

London

$(-3.33)$

0.01

(0.31)

South West

$-0.02$

0.03

$(-0.30)$

(0.95)

Scotland

$-0.1$

$-0.05$

$(-1.37)$

$(-0.89)$

Wales

$-0.14 *$

$-0.08$

$(-1.68)$

$-0.002$

$(-1.05)$

Number of Employees*100

$(-0.69)$

$-0.12 *$

$(-1.73)$

$(-0.47)$

Public sector

$(-2.41)$

Workforce composition:

Largest non-managerial occupation (ref.: Professionals):

Associate Professionals

$$
0.06
$$

$-0.02$

(0.72)

$(-0.68)$

Administrative and Secretarial

$-0.02$

$-0.02$

$(-0.20)$

$(-0.65)$

Skilled Trades

(4.06) 


\begin{tabular}{|c|c|c|c|c|}
\hline Caring, Leisure, Other Service & $\begin{array}{l}0.08 \\
(1.04)\end{array}$ & & ${ }^{(-0.61)^{-0.02}}$ & \\
\hline Sales and Customer Service & 0.07 & & -0.04 & \\
\hline & $(0.87)$ & & $(-0.88)$ & \\
\hline Process, Plant and Machine Operatives & 0.37 & $* * *$ & 0 & \\
\hline & (3.28) & & $(-0.04)$ & \\
\hline Elementary & 0.14 & & -0.05 & \\
\hline & $(1.52)$ & & $(-0.90)$ & \\
\hline Percent female*100 & -0.392 & $* * *$ & 0.069 & \\
\hline & $(-4.09)$ & & $(1.53)$ & \\
\hline Contracts: & & & & \\
\hline Shift-working (Ref: no) & & & & \\
\hline Yes & 0.09 & $* *$ & -0.02 & \\
\hline & $(2.27)$ & & $(-0.83)$ & \\
\hline Don't know & -1.09 & $* * *$ & -0.28 & * \\
\hline & $(-7.37)$ & & $(-1.95)$ & \\
\hline Work organisation: & & & & \\
\hline Fully autonomous team-working & 0.04 & & -0.05 & $* *$ \\
\hline & $(0.90)$ & & $(-2.22)$ & \\
\hline$\%$ core employees in teams & 0 & & 0.01 & $* * *$ \\
\hline & $(-0.57)$ & & $(3.13)$ & \\
\hline Functional flexibility (Ref.: no) & & & & \\
\hline Yes & 0.08 & $* *$ & -0.06 & $* * *$ \\
\hline & $(2.26)$ & & $(-3.09)$ & \\
\hline Don't know & -0.01 & & -0.22 & \\
\hline & $(-0.15)$ & & $(-1.50)$ & \\
\hline Number of incentive schemes & -0.03 & $*$ & 0.01 & \\
\hline & $(-1.91)$ & & $(1.43)$ & \\
\hline Job autonomy scale & 0 & & 0.01 & $* * *$ \\
\hline & $(-0.58)$ & & $(3.20)$ & \\
\hline HRM practices: & & & & \\
\hline Targets for absence & -0.04 & & -0.04 & * \\
\hline & $(-0.86)$ & & $(-1.90)$ & \\
\hline Targets for employee job satisfaction & 0.03 & & 0.06 & $* *$ \\
\hline & $(0.61)$ & & $(2.50)$ & \\
\hline Targets missing & -0.02 & & 0.15 & \\
\hline & $(-0.16)$ & & $(1.15)$ & \\
\hline Sick pay (ref.: no entitlement above sta & ory) & & & \\
\hline Only managers > statutory & -0.01 & & 0.01 & \\
\hline & $(-0.09)$ & & $(0.45)$ & \\
\hline Only non-managers > statutory & 0.07 & & -0.2 & \\
\hline & $(0.73)$ & & $(-1.55)$ & \\
\hline Both > statutory & -0.04 & & -0.01 & \\
\hline & $(-0.92)$ & & $(-0.68)$ & \\
\hline Don't know & -0.6 & $* * *$ & 0.04 & \\
\hline & $(-3.30)$ & & $(0.74)$ & \\
\hline ining (Ref.: no) & & & & \\
\hline Yes & 0.16 & $* * *$ & 0.02 & \\
\hline
\end{tabular}




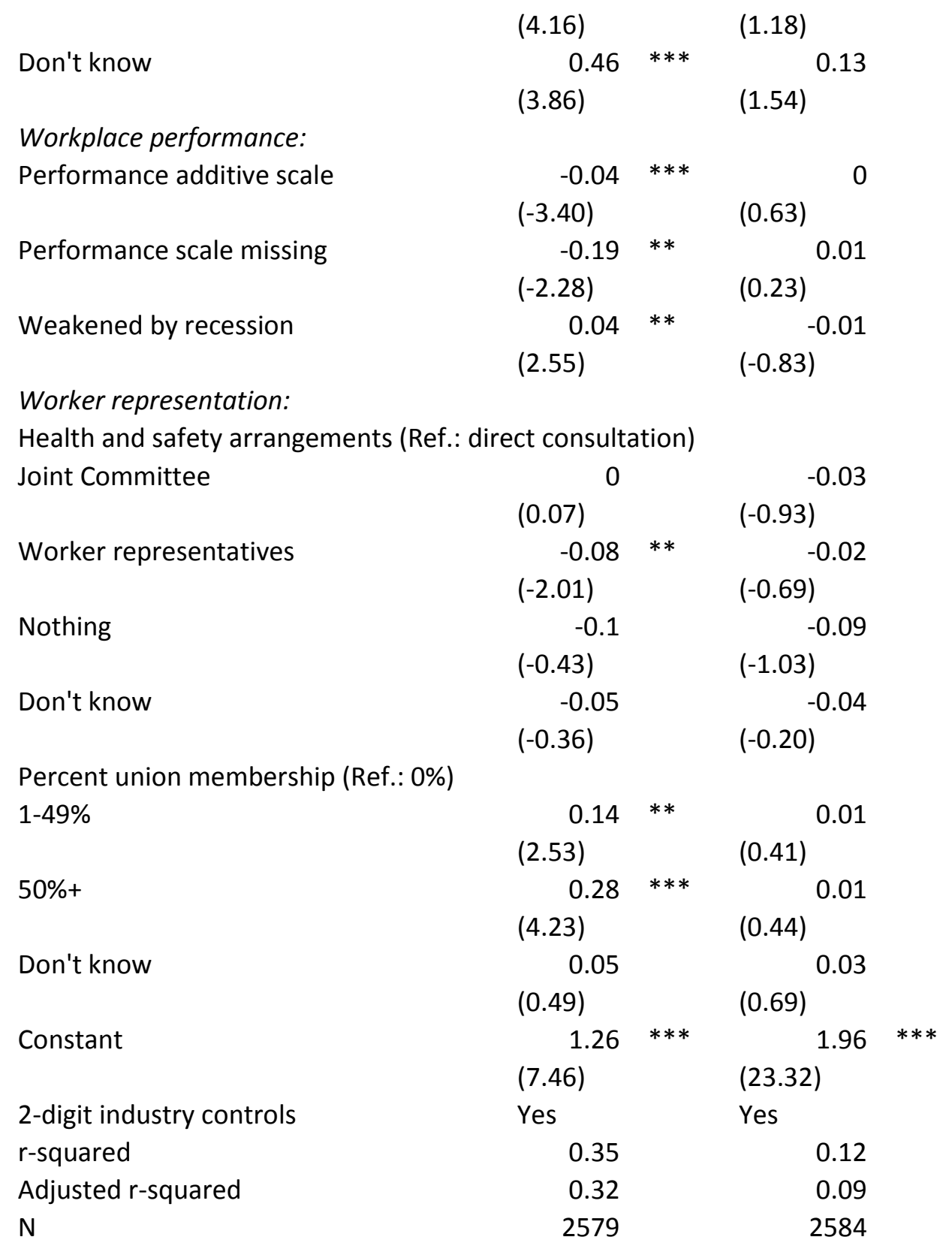

